\title{
Unsustainable Paradoxes Inherent in the International Legislation of Electronic Waste Disposal
}

\author{
Julian Scott Yeomans ${ }^{*}, 1$ and Yavuz Günalay ${ }^{2}$ \\ ${ }^{1}$ Operations Management and Information Systems Area, Schulich School of Business, SSB S338, York University, To- \\ ronto, ON, M3J 1P3, Canada \\ ${ }^{2}$ Faculty of Business, Bahcesehir University, Osmanpasa Mektebi St. No:4-6, 34100 Besiktas Istanbul, Turkey
}

\begin{abstract}
New waste management legislation provides a driver for materials recovery, industrial ecology, and remanufacturing practices throughout the global electronics industry. Paradoxically, the resulting regulations are incongruent and unsustainable because the targeted practitioners can neither legally re-use the resultant reclaimed materials nor legally store or dispose of the ensuing wastes.
\end{abstract}

\section{INTRODUCTION}

The essential principle underlying the practice of industrial ecology is that industrial systems need to mimic the behaviorof natural ecosystems by having all discarded, returned, or otherwise spent manufacturing products used as raw material inputs in subsequent manufacturing operations [1-3]. In closed-loop industrial ecosystems, the raw material input requirements of manufacturing processes are met by the wastes supplied from the discarded products.

While the recovery and recycling infrastructure is well developed for non-durable products, the recovery of durable (and semi-durable) goods produces numerous challenges that differentiate the process from that required for consumable goods. These differences are generally based upon the delay and uncertainty associated with the availability of these goods for recovery. For the case of consumable products, sales and previous use can be used as the prime indicators of future availability. However, this predictability is frequently not possible with durable products, since these goods possess wide variations in use, failure and storage behavior. The major difference between disposal, recovery and processing of durables versus non-durables lies in the uncertainty related to timing. For both durable and non-durable products, the user generally decides how to use the product and at what point to dispose of the used product. But the difference in the duration of product usability for durable and non-durable goods ensures that the disposal of non-durable goods is easy to predict, since they must usually be consumed quickly and disposed of immediately once consumption has occurred. Durable goods, however, vary tremendously in terms of functional life and the intensity of their use. Furthermore, durable goods are often stored for varying lengths of time after the conclusions of their functional lives. Consequently, with attention and legislation now shifting away from the recovery of consumable goods toward durable products, variation

*Address correspondence to this author at the Operations Management and Information Systems Area, Schulich School of Business, SSB S338, York University, Toronto, ON, M3J 1P3 Canada; Tel: (416) 736-5074; Fax: (416) 736-5687; E-mail: Syeomans@schulich.yorku.ca in life and storage by product users must now be considered for policy formulation, development of collection and processing infrastructure and to increase the likelihood that recovered durable goods will be used as an input for applications that have low environmental impact and/or high economic value-added (i.e. for the practice of industrial ecology). Such consideration is imperative since policy makers, due to their prior experiences with the relatively constant flows of non-durable wastes, have maintained a tendency to assume that durable good waste flows will also remain relatively constant.

Environmentally sustainable closed-loop production, consumption, and disposal systems occur only when the supply and demand for the industrial wastes are exactly balanced. In order to invest in the necessary physical plant, product development, and manufacturing, firms engaging in industrial ecology must now simultaneously demonstrate not only that market demand exists for their products, but also that the supply of raw materials required for manufacture will be available in sufficient quantities exactly at the required production time. Hence, companies must be able to predict the likely supply of the needed waste material in the face of considerable uncertainty prior to engaging in any industrial ecology activities. If it can be ascertained that a steady flow of waste would be attainable over a sufficiently long time horizon at an acceptable price, then this waste stream could be considered as an economically viable, raw material input source. However, since companies cannot control the failures and subsequent disposal of durable products, they can never determine explicitly whether sufficient quantities of the requisite waste would be available for input. If waste streams are to become the effective manufacturing input required for industrial ecology, then many of the planning and management issues surrounding the inherent uncertainty of the timing and availability of the waste supply must be satisfactorily resolved, a priori. Consequently, one of the major challenges faced by companies is to effectively manage the supply uncertainties inherent in using durable product discards as their raw material input for manufacturing.

Several recent pieces of legislation mandating the adoption of industrial ecology practices have been enacted to 
promote industrial ecology and sustainable activities for durable products within the global electronics industry. Resource recovery from durable electronic products provides a timely illustration of the recovery challenges created by enforced industrial ecology, since concurrent legislation has also been passed requiring their remanufacturing into alternative products in North America, Europe, and Asia, while simultaneously banning their disposal in landfills and incinerators [4-11]. The goal of these new regulations is to prevent a significant source of hazardous waste from entering into the eco-system, since durable electronic products contain numerous toxic substances (particularly heavy metals) including lead, mercury, cadmium, phosphorus, hexavalent chromium, barium, polybrominated biphenyls (PBB), and polybrominated diphenyl ether (PBDE). To address the forecasting requirements necessary for the practice of industrial ecology, Linton \& Yeomans and Linton et al. have demonstrated with certainty that significant quantities of the metals recoverable from electronic products can be expected to continuously enter the waste stream over the course of the next 50 years in a form considered ideal for post-consumer remanufacturing purposes $[1-3,12]$. Therefore, the legislation banning electronic waste disposal in combination with the mandated remanufacturing requirements should lead to numerous financially attractive business ventures for the reprocessing and recycling of these waste metal streams.

Unfortunately, while the motivation behind the re-use of post-consumer wastes is environmentally well-intentioned, the enforced industrial ecology legislation for durable electronic products may, instead, conversely produce significant unsustainable environmental consequences. This is because it can be demonstrated that a significant proportion of the durable electronic products are not conducive to end-of-life industrial eco-system practices, due to the facts that they: (i) obviously contain materials that engender considerable public health concerns; (ii) are in the declining-market stage of their product lifecycles, and; (iii) are considerably threatened by technological obsolescence. Furthermore, other studies have revealed that manufacturing companies have redesigned their products without the use of these metals as production inputs, resulting in essentially no demand for their use in any of their newly manufactured product-lines [13, 14]. In addition, several international legal conventions have been instituted that effectively prevent any international transboundary movement of hazardous wastes [15-17]. Consequently, by eliminating all legal means for both withinand between- country disposal, concurrent with the limited and declining applications for reprocessing, the enforced introduction of industrial ecology practices for durable electronic wastes will necessarily create a supply-demand imbalance that is unsustainable and will inevitably produce significant hazardous waste material storage repercussions.

\section{DURABLE ELECTRONIC WASTES AS A SUPPLY SOURCE FOR POST-CONSUMER REMANUFAC- TURING}

Linton et al. and Linton \& Yeomans extensively examined several alternative approaches for estimating waste disposal and resource recovery patterns from different types of long-lived durable electronic products $[1,3,12]$. Though sales and previous usage serve as the primary indicators for the availability of wastes from consumable products [18-20], due to the much wider variability in their use, failure rates, and post-failure storage behaviorthis is not the case for longlived durable electronic goods $[3,21,22]$. In particular, estimates of future electronic waste streams require effective technological forecasting of household disposal patterns [21, $22]$, which proves to be an extremely challenging problem involving many uncontrollable and stochastically uncertain elements [1, 12]. Linton et al. described how the major sources of waste stream uncertainty require estimations of; the stage of the product lifecycle, the component weights

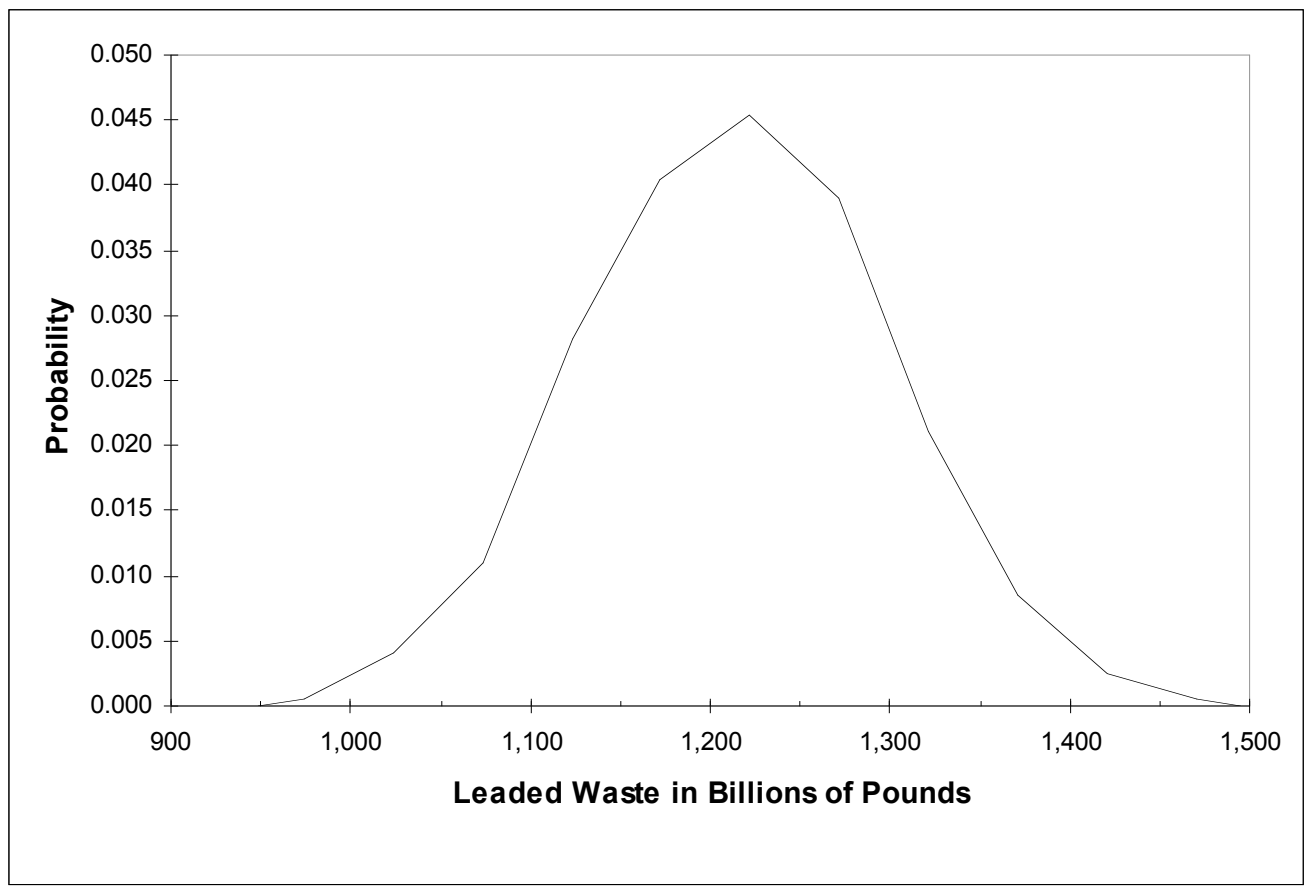

Fig. (1). Quantity of recoverable lead residing in north american CRT televisions. 
containing the recoverable materials, the time between failure and entry into the waste stream, reclamation proportions, future sales, and the rates at which alternate technology displace the existing technology [3].

For example, using historical data and stochastic estimators of the other uncertainties, Linton et al. ([3]) showed that an effective approximation of the total existing quantity of lead currently residing in the cathode ray tubes (CRTs) of North American households could be estimated by the probability distribution shown in Fig. (1).

Linton et al. then combined historical television sales data with forecasted future television sales to project the future CRT waste stream onto the time horizon between the years 2000 and 2050 [3]. In addition to the forecast of the number of televisions sold over the course of this period, this projection had to incorporate the displacement effect from possible future competing technologies. This need to incorporate the new technology component was essential due to the impending technological obsolescence of CRTs through replacement by technologically superior flat-panel (FP) displays together with the mandated switch from analog to digital broadcasting (to high definition television, HDTV) by the Federal Communication Commissions (FCC) in the United States. This was achieved by considering several different plausible technology displacement scenarios. The most conservative displacement scenario was one in which all CRT television sales effectively ceased immediately - implying that all future lead waste from CRTs could result only from televisions already in existence. Fig. (2) illustrates the waste trajectory recovery pattern for the 2000-2050 period under this scenario. Hence, it could be observed that even if all existing CRT television sales ceased immediately, a significant supply of leaded CRT wastes would be entering into the waste stream over the next 50 years. Fig. (3) illustrates the recovery pattern under a scenario in which CRT televisions continued to be sold at or above their current volumes.
Consequently, these figures clearly indicate that significant quantities of lead waste from CRTs would be recovered well into the foreseeable future. The existence of these exceedingly large quantities of leaded wastes over such a protracted period of time would seem to bode extremely well for their inclusion in the practice of industrial ecology mandated by the new legislation.

More significantly, the above estimation approaches were subsequently extended to numerous other product-lines of durable electronic goods and similar supply trajectory patterns were demonstrated for several other metals contained within these products $[1,2]$. The net beneficial result from all of these research findings is that significant supplies of various metals can be expected to be continuously entering the various waste streams over a protracted period of time in a form that can be considered as ideal for post-consumer remanufacturing applications. Thus, legislation banning electronic product disposal together with the mandated remanufacturing requirements should lead to several numerous potentially attractive business ventures for the reprocessing and recycling of the very high metal contents found within these durable electronic waste streams $[1,12]$.

\section{LACK OF DEMAND FOR ELECTRONIC WASTES IN POST-CONSUMER REMANUFACTURING AND ITS CONSEQUENCES}

The measure of the true success of industrial ecology, remanufacturing, and reverse logistics does not occur until the supply and demand loop has been completely closed [21, $22]$. In closing the supply and demand loop, the primary differences between views of traditional "business-based" manufacturing practices and those of the more recent "industrial ecology-based" remanufacturing philosophies revolve around the processes by which the waste material supplies can be effectively reconciled with the product demands of the subsequent consumers. While proponents of the indus-

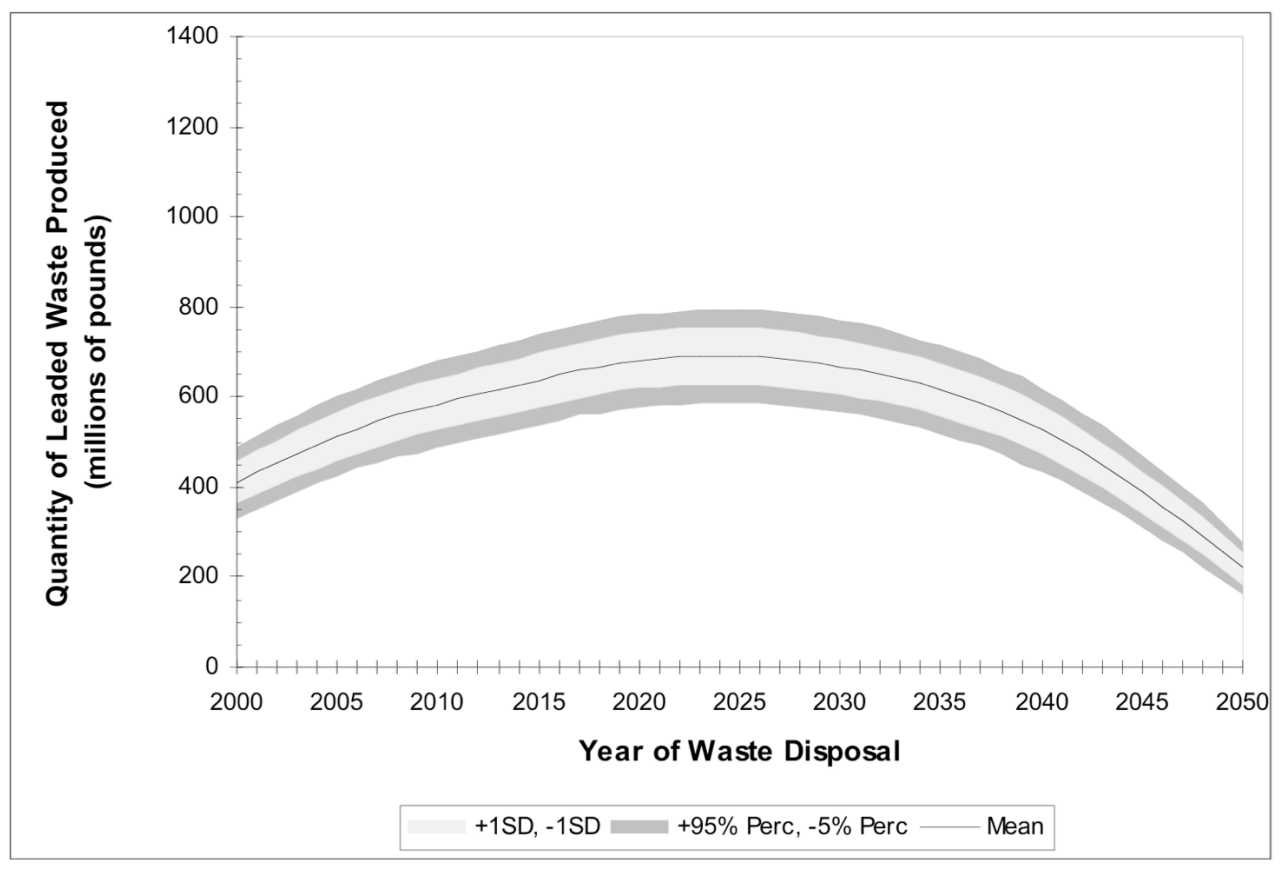

Fig. (2). Leaded CRT waste recovery trajectory under a scenario in which CRT television sales cease immediately. 


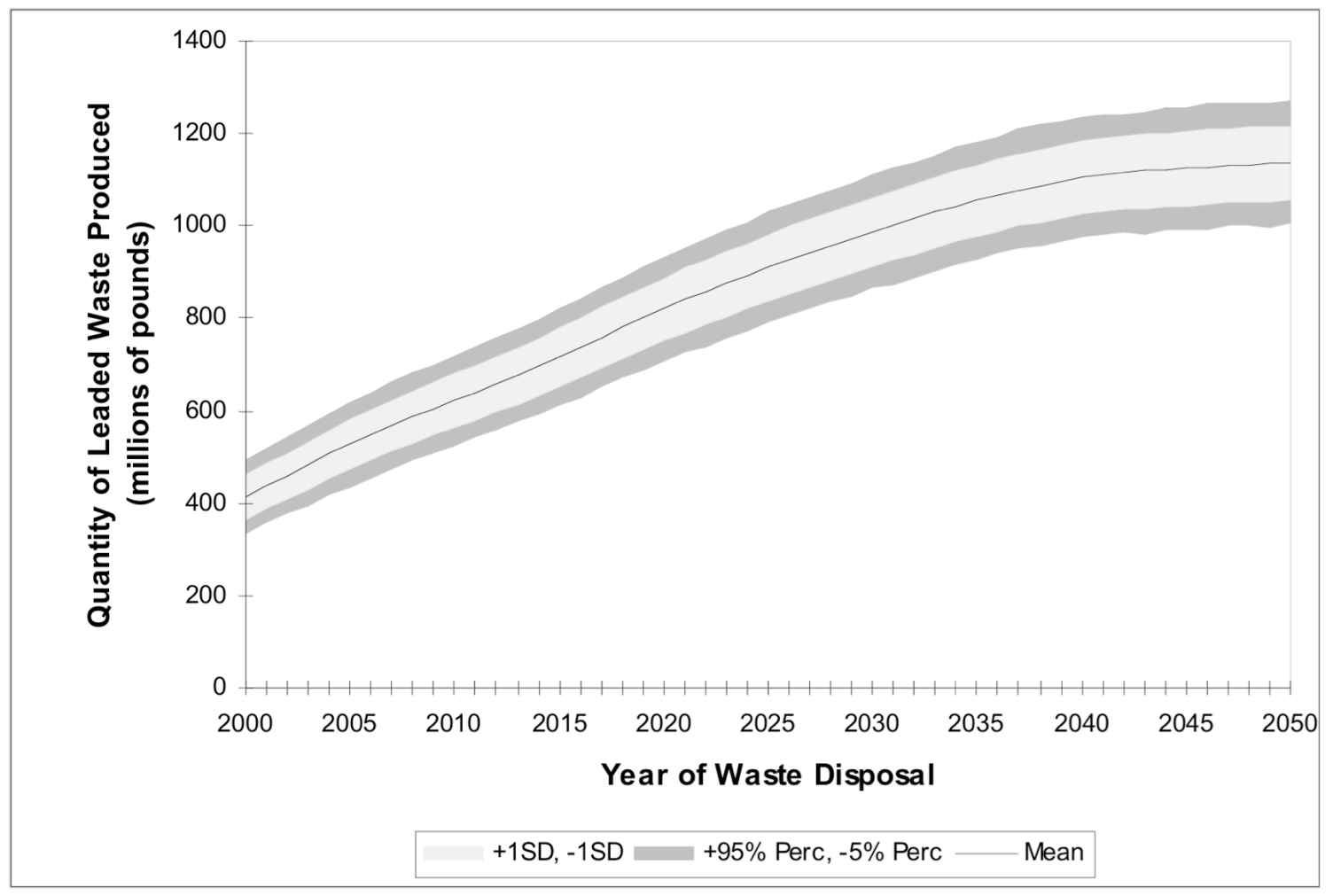

Fig. (3). Leaded CRT waste recovery trajectory under a scenario in which CRT television sales continue at or above their current volumes.

trial ecology-focused viewpoint would prefer to exactly match all waste product disposal with product supply, business-focused proponents would prefer to utilize only a small proportion of the disposed wastes to ensure that the raw material base (i.e. the disposed waste product) is readily available at a low price [3]. Reconciling these divergent philosophies is, therefore, an essential component for the effective implementation of industrial ecology, since the two concepts require that the greatest economic value be obtained from the waste while simultaneously resulting in the smallest environmental impact. Hence, if industrial ecology-based remanufacturing of electronic wastes is to be effectively operationalized, then appropriate mechanisms for balancing the requirements of both industrial ecology-based operations and traditional business manufacturing practices must be implemented that integrate the supply of the disposed wastes with the corresponding industrial demand for the metals (and all other waste materials). The fundamental key to its success is the establishment of the effective balance between the waste supplies and the product input demands [21].

However, in studying manufacturing practices in North America, Halluite et al. discovered that virtually all companies have now moved away from the consideration and use of the vast majority of these toxic metals in the design of their new electronic product-lines [14]. Furthermore, in the existing markets for the electronic waste metals, current recycling programs are already reclaiming substantial quantities of the required and targetted materials. The combination of these findings is that most of the electronic metals currently being used are already being recovered from secondary sources and, simultaneously, the demand for metals obtained from primary sources has declined precipitously $[13,14]$.
Simultaneously, the legislation banning electronic waste disposal from landfilling and incineration will result in the immediate consequence of injecting a large new source of secondary materials into the "marketplace". While this has the environmentally beneficial effect of immediately reducing the demand for these metals from primary sources, given the identified diminution in industrial demand, the increased supply of the metals provided by these electronic wastes far outstrips any existing or possible future demand, leading to a unsustainable supersaturation of the market $[13,14]$. Thus, either major new applications must be found for these large quantities of waste or significantly large new storage locations become requisite. However, the recent "environmentally conscious" practices of benign manufacturing, sustainability, and future-liability-avoidance have resulted in the simultaneous elimination of many hazardous materials from being used as inputs in the design of the vast majority of new products $[13,14]$. As a result, the current demand for electronic waste metal inputs in newly-manufactured products has become virtually non-existent $[13,14]$.

What becomes readily apparent is that the changes to product compositions, designs and technological bases have created significant and unsustainable problems for the newly legislated industrial ecology policies. The elimination of all legal means for electronic waste disposal, concurrent with the limited and declining markets for all of the reprocessed metals, causes significant supply-demand imbalances for the resulting market oversupply from the electronic wastes. Under these circumstances, the regulations that had been intended to encourage sustainability and industrial ecology instead produce unintended, but very significant, negative, secondary environmental consequences. Namely, with no outlets for the recovered toxic metals in any remanufactured 
products, the net effect of the enforced industrial ecology practices is to introduce long-term hazardous waste storage issues for all of the resulting electronic wastes.

The significant implications from these findings regarding induced - but unintended - storage requirements extend to all of the well-intentioned industrial ecology-based legislation targetted at the recycling and remanufacturing of industrial wastes. While from a relatively narrow, technical perspective most industrial and municipal wastes can always be considered recoverable, recyclable, and reusable [22], the major impediment to waste recovery always lies in the finding of appropriate outlets for the recovered materials that simultaneously make economic, political, environmental, and psychological sense [21]. The supply of waste products available as raw material inputs is generally never the constraining issue. However, the requisite conditions for achieving truly sustainable closed-loop industrial ecology cannot occur until someone actually purchases (or is paid to take) the recovered materials, manufactures them into something else, and then resells this new product. When a lack of demand for the recovered materials exists, the market for the waste products rapidly becomes oversaturated with the excess materials - filling up as quickly as the landfills that the waste had originally been diverted from.

The frequently overlooked message for those (generally well-intentioned) bodies trying to legislate industrial ecology practices is that they must completely understand and pay close attention to these market imbalances. When the primary concern of the legislation is to increase the supply of the recovered materials rather than to expand the markets for the recyclable materials, then the enforced industrial ecology legislation must be readily assessed with a certain degree of skepticism. Unfortunately, this expansion in supply without regard to demand appears to be the overriding condition induced by the industrial ecology legislation directed at the durable electronic waste products. The combined conditions of significant over-supply with no legal disposal outlet must inevitably lead to the secondary storage issues mentioned previously.

Clearly, societal concerns regarding the use of toxic materials in remanufacturing and the subsequent trade-offs associated with their post-consumer-use disposition have to be addressed ahead of time, so that appropriate and/or suitable decisions can be made and supporting infrastructure can be sufficiently developed. Properly conceived and executed, an industrial ecology program can make very good economic sense, can help save natural primary resources, can help reduce pollution, and can divert the tributaries of the waste streams away from disposal in landfills and incinerators. However, the best of environmental and ecological intentions established by regulations for the remanufacturing and reprocessing of consumer goods (such as that described for the durable electronic products) become egregiously misplaced when all of the targeted practitioners of the industrial ecology directives have no propensity to engage in the re-use of the resultant waste materials. It must be recognized that while industrial ecology is a valuable philosophy for coping with society's waste, it is by no means a panacea when the remanufacturing loop cannot be successfully closed. As illustrated above, the enforced implementation of industrial ecology practices using electronic wastes will not be sustain- able until this supply and demand loop has been effectively closed.

\section{CONCLUSION}

In reality, there can be very little opposition to supporting the premise that adopting sustainable manufacturing practices should provide improvements to the state of environment. However, several recent initiatives taken to reduce the negative ecological impacts and effects of industrial activities could, in fact, be unsustainable, by having precisely the opposite impact from their stated goals. Regulations banning the landfilling and incineration of durable electronic products are environmentally very well intentioned, with their goal being to prevent a significant source of hazardous waste from subsequently entering the eco-system. It can be demonstrated that these regulations will generate a significant pulse of electronic wastes that will enter the waste stream over a considerable period of time into the foreseeable future. The beneficial effect of these findings for industrial ecology purposes is that significant quantities of various metals will be continuously available over a protracted time horizon in a form that is ideal for post-consumer remanufacturing purposes. The new disposal legislation together with mandated post-consumer remanufacturing requirements should necessarily, therefore, lead to numerous economically attractive business ventures for reprocessing and recycling the high metal content existing in the electronic wastes. Thus, the legislation in Europe, Asia, and North America should provide a strong incentive for and significant driver of industrial ecology, materials recovery, and remanufacturing practices throughout the global electronics industry.

However, most durable electronic products do not prove suitable for end-of-life industrial eco-system practices, since they: (i) contain materials that engender considerable public health concerns; (ii) are in the declining-market stages of their lifecycles, and; (iii) are considerably threatened by technological obsolescence. As electronic manufacturers are forced to move away from the use of several substances in their production inputs, the industrial ecology legislation actually creates a state of zero demand for their use as inputs in any newly-designed manufactured products. Consequently, by eliminating all legal means for disposal, concurrent with the limited and/or non-existent applications for reprocessing, the enforced introduction of industrial ecology practices for electronic wastes creates an unsustainable supply-demand imbalance that will inevitably lead to large, long-term hazardous waste storage problems.

Industrial ecology, remanufacturing, and reverse logistics are founded on the premise that industrial wastes can be economically redirected into alternative products and should be strived for wherever possible. While environmental policies that promote sustainability and industrial ecology principles offer advantages in stable industrial settings, their anticipated benefits can be significantly confounded by changes to the product designs of durable goods due to scientific and technological advances and to the introduction of more environmentally benign designs. The regulatory paradox that has to be resolved is that legislation requiring product take-back and waste product reprocessing generally focuses on products and materials that are seen as undesirable components of landfills, but these products consequently all contain sig- 
nificant quantities of undesirable components that must somehow be used as the raw material inputs in some alternative product. Unless the impacted products possess both stable designs and input requirements, then it becomes apparent that significant secondary, unsustainable environmental issues related to waste storage will arise - which is the case that has been demonstrated for durable electronic product wastes.

Consequently, although industrial ecology laws are wellintentioned, they become relatively unsustainable and create alternative environmental problems when absolutely no market or alternative outlet exists for the specific waste product. To avoid unsustainability problems in the future, appropriate forethought must now be directed to the long-term outcomes of the newly enforced industrial ecology policies. While the electronics industry has been the first to encounter such industrial ecology and reprocessing legislation on a global scale, similar consequences can also be expected to any similar directives targeted at other durable goods manufacturers.

\section{ACKNOWLEDGEMENT}

This work was supported in part by grant OGP0155871 from the Natural Sciences and Engineering Research Council.

\section{REFERENCES}

[1] Linton J, Yeomans JS. The role of forecasting in sustainability. Technol Forecast Soc Change 2003; 70(1): 21-38.

[2] Linton J, Yeomans JS. Materials recycling and industrial ecology. Nat Mater 2004; 3(4): 199-201.

[3] Linton J, Yeomans JS, Yoogalingam R. The facilitation of industrial ecology, product take-back, and sustainability through the forecasting of television waste flows. Environ Inf Arch 2004; 2(4): 420-31.

[4] Department of Environmental Protection, Hazardous and solid waste regulations for Massachusetts: 310 CMR 30.000 and 310 CMR 19.00, Public hearing draft regulations for the management of discarded cathode ray tubes. Boston, MA: DEP 1998.

[5] Department of Environmental Protection, FL 2002, Focus on Televisions and Computer Monitors: Lead. Available from: www.dep.state.fl.us/waste/categories/electronics/pages/lead.htm
[6] Environmental Protection Agency. Residential collection of household end-of-life electrical and electronic equipment. EPA901-R-98-002. Boston, MA: EPA 1998.

[7] European Union, Directive 2002/96/EC of the European Parliament and of the Council of 27 January 2003 on Waste Electrical and Electronic Equipment (WEEE). Off J Eur Union 2003; L37, 46: 2439.

[8] Federal Register. Hazardous Waste Management System; Modification of Hazardous Waste Program; Cathode Ray Tubes and Mercury Containing Equipment; proposed rule. Environ Prot Agency 2002; 67(113): 40507-28.

[9] Linton J. Electronic products at their end-of-life: Options and obstacles. J Electron Manuf 1999; 9(1): 29-40.

[10] State of California, Electronic Waste Recycling Act of 2003 (SB 20) SHER, Statutes of 2003, CA: USA 2003.

[11] State of Minnesota Statute 115A.9565. Minneapolis, MN: USA 2003.

[12] Linton J, Yeomans JS, Yoogalingam R. Supply planning for industrial ecology and remanufacturing under uncertainty: a numerical study of leaded-waste recovery from television disposal. J Oper Res Soc 2002; 53(11): 1185-96.

[13] Halluite J. Leaded glass and lead diversion from US Landfills. MASc, Thesis. Polytechnic University, Brooklyn, NY: USA 2002.

[14] Halluite J, Linton J, Yeomans JS, Yoogalingam R. The challenge of hazardous waste management in a sustainable environment: insights from electronic recovery laws. Corp Soc Respons Environ Manage 2005; 12(1): 31-7.

[15] Basel, Basel Convention on the Control of the Transboundary Movements of Hazardous Wastes and Their Disposal. 1989; Available from: www.basel.int/text/documents.html

[16] Rotterdam, Rotterdam Convention on the Prior Informed Consent Procedure for Certain Hazardous Chemicals and Pesticides in International Trade. 1998; Available from: www.pops.int

[17] Stockholm, Stockholm Convention on Persistent Organic Pollutants. 2001; Available from: www.pic.int

[18] Kelle P, Silver EA. Forecasting the returns of reusable containers. J Oper Manage 1989; 8(1): 17-35.

[19] Kelle P, Silver EA. Purchasing policy of new containers considering the random returns of previously issued containers. IEEE Trans 1989; 21(4): 349-54.

[20] Toktay LB, Wein LE, Zenios SA. Inventory management of remanufacturable products. Manage Sci 2000; 46(11): 1412-26.

[21] Rathje W, Murphy C. Rubbish! The archaeology of garbage, University of Arizona Press, Tucson AZ: USA 2001.

[22] Tchobanoglous $G$, Thiesen $H$, Vigil S. Integrated solid waste management: engineering principles and management issues. McGraw-Hill New York, NY: USA 1993. 